\title{
Effects of Hot Isostatic Pressing on Microstructure and Mechanical Properties of Hastelloy X Samples Produced by Selective Laser Melting
}

\author{
Yali $\mathrm{Li}^{1, \mathrm{a}}$, Hai Qi ${ }^{2, \mathrm{~b}}$, Huipeng Hou ${ }^{1, \mathrm{c}}$, Liming Lei ${ }^{1, \mathrm{~d}}$ \\ ${ }^{1}$ Research Center for Processing, AECC Shanghai Commercial Aircraft Engine Manufacturing \\ Co.,Ltd, Shanghai, 201306, China \\ ${ }^{2}$ Department of Powder Material, Shanghai Research Institute of Materials, Shanghai, 200437, \\ China \\ ayalili_nuaa@163.com, ${ }^{b} 18221057671 @ 163 . c o m,{ }^{c} 13917176841 @ 163 . c o m,{ }^{d}$ biamfirst@126.com
}

Keywords: Hot isostatic pressing, Hastelloy X, Selective laser melting, Microstructure, Mechanical property.

\begin{abstract}
Hot isostatic pressing (HIP) with two different temperatures of $1100{ }^{\circ} \mathrm{C} / 160 \mathrm{MPa} / 2 \mathrm{~h}$ and $1175^{\circ} \mathrm{C} / 160 \mathrm{MPa} / 2 \mathrm{~h}$ was performed on Hastelloy $\mathrm{X}$ samples produced by selective laser melting (SLM) was performed. The effect of hot isostatic pressing on defects, microstructures and mechanical properties of SLM fabricated Hastelloy X samples were investigated. It showed that cracks and micro-pores on within SLM-fabricated samples were gradually eliminated with the increase of HIP temperatures, increased A in which nearly fully dense part can be achieved at hot isostatic pressing of $1175{ }^{\circ} \mathrm{C} / 160 \mathrm{MPa} / 2 \mathrm{~h}$. The microstructure evolution rule as follows: cellular crystal in both horizon and vertical directions, no precipitates (as-deposited) $\rightarrow$ equiaxed crystal with size of $10-50 \mu \mathrm{m}$ in horizon direction and columnar crystal with size of $200 \mu \mathrm{m}$ in vertical direction, chain-like precipitates distributed at grain boundaries $\left(1100{ }^{\circ} \mathrm{C} / 160 \mathrm{MPa} / 2 \mathrm{~h} \mathrm{HIP}\right.$ processed) $\rightarrow$ equiaxed crystal with size of $150 \mu \mathrm{m}$ in both horizon and vertical directions, plate-like precipitates distributed at grain boundaries with size triple increased $\left(1175{ }^{\circ} \mathrm{C} / 160 \mathrm{MPa} / 2\right.$ $\mathrm{h}$ HIP processed). Ductile fracture occurred in both SLM deposited and HIP processed samples during room temperature tensile tests, while all tested samples behaved higher mechanical properties than traditional wrought parts. The room temperature tensile properties of the as-deposited and the two HIP processed samples all reached the standard for wrought Hastelloy X. Moreover, the ductility of HIP processed samples enhanced and tensile properties decreased compared with SLM deposited samples.
\end{abstract}

\section{Introduction}

Hastelloy-X alloy is a solid solution strengthening nickel base superalloy, the main solid solution strengthening elements of which are Mo, W and Cr. It has good corrosion resistance and oxidation resistance. The alloy has good high-temperature performance and can be used for a long time under $900{ }^{\circ} \mathrm{C}$. It is mainly used to fabricate blades, combustor parts and other high-temperature components of aeroengine. Although there have been many researches carried out on the Hastelloy series alloys up to date, most of them were focused on traditional preparation routes of these alloys, such as rolling and casting [1-4]. In this study, selective laser melting (SLM) method was used to prepare Hastelloy X alloy components.

Selective laser melting is presently one of the most promising additive manufacturing techniques. In this method, a high energy laser beam is used to melt the powder material layer by layer according to the CAD data of the part, thus creating high density three-dimensional parts [5]. SLM is highly time and cost efficient, compared with traditional casting and forging methods [6,7], and has been applied to a wide range of industries, including the aerospace, biomedical, mold and other industries.

However, due to the rapid melting and solidification of the powdery material during the SLM process, the temperature, temperature gradient and volume change dramatically, resulting in the 
accumulation of internal stress and cracking in SLM manufactured components. In addition, there is a gap between the particles during the spherical powder particles spread, while in the process of powder material melt under laser irradiation, the faster solidification tends to induce the liquid phase spreading unfully and thus creating micro-pores. These defects adversely affect the end-use properties of the SLM parts. By adopting the hot isostatic pressing (HIP) treatment, which is widely used both domestically and overseas, the above mentioned defects can be effectively eliminated, and the density of the components can be improved [8-10].

In this study, the SLM fabricated Hastelloy X alloy components were subjected to HIP treatment. The effects of HIP treatment on eliminating SLM defects, the material microstructure and mechanical properties were investigated.

\section{Material and Methods}

Experimental Material. Hastelloy X powders were used in the current study, and their chemical composition is shown in Table 1. The powders possessed a spherical shape, with the particle size distribution of $15 \mu \mathrm{m} \sim 45 \mu \mathrm{m}$ (Fig. 1). Prior to laser process, the powders were subjected to a vacuum drying process to remove the moisture adsorbed. In addition, a carbon steel substrate was cleaned with alcohol.

Table 1. Chemical composition of Hastelloy $\mathrm{X}$ alloy powder.

\begin{tabular}{cccccccccccc}
\hline Element & $\mathrm{Ni}$ & $\mathrm{Cr}$ & $\mathrm{Fe}$ & $\mathrm{Mo}$ & $\mathrm{Co}$ & $\mathrm{W}$ & $\mathrm{B}$ & $\mathrm{Mn}$ & $\mathrm{C}$ & $\mathrm{P}$ & $\mathrm{S}$ \\
\hline Mass/\% & 48.58 & 21.58 & 18.59 & 8.91 & 1.52 & 0.6 & $<0.002$ & 0.014 & 0.082 & $<0.002$ & 0.002 \\
\hline
\end{tabular}
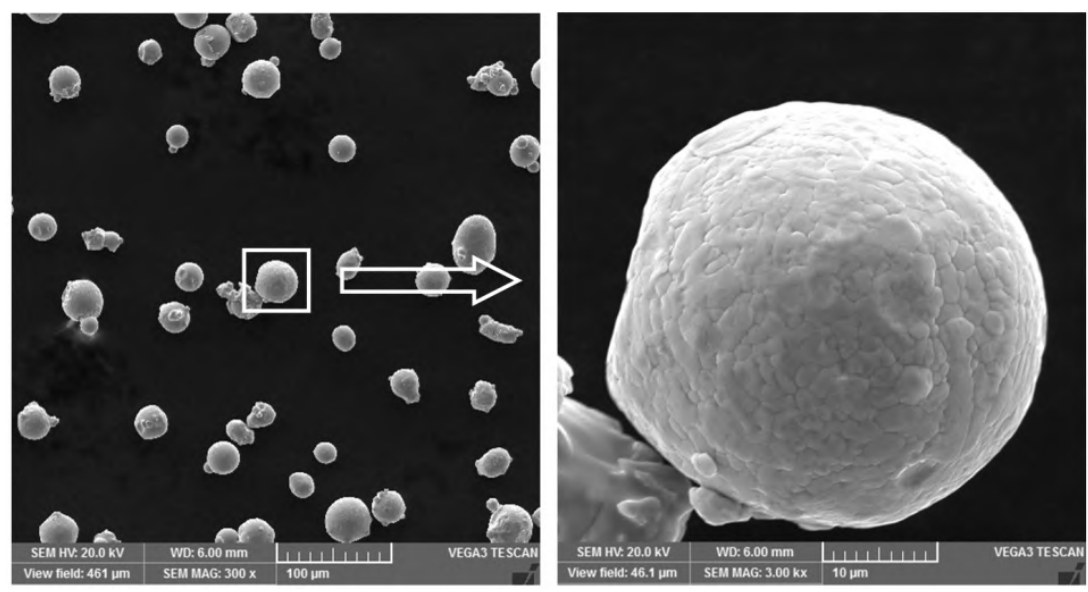

Fig. 1 SEM images of Hastelloy-X alloy powders.

Table 2. Process parameters for selective laser melting of Hastelloy-X powder.

\begin{tabular}{cc}
\hline Parameter & Value \\
\hline Layer thickness, $d$ & $20 \mu \mathrm{m}$ \\
Spot diameter, $D$ & $100 \mu \mathrm{m}$ \\
Hatch spacing, s & $90 \mu \mathrm{m}$ \\
Preheating temperature, $T_{0}$ & $80^{\circ} \mathrm{C}$ \\
Laser power, $P$ & $200 \mathrm{~W}$ \\
Scan speed, $v$ & $1100 \mathrm{~mm} / \mathrm{s}$ \\
Rotation angle of laser & $67^{\circ}$ \\
scanning direction &
\end{tabular}


Samples Prepared. The Hastelloy X samples used for tensile tests were prepared using an EOS M280 SLM machine. Argon gas was fed into the sealed building chamber. The samples were oriented parallel to the laser beam direction ( $\mathrm{z}$ axis). The processing parameters used in this study are listed in Table 2. The samples were cut off from the substrate by electro-discharge machining after the SLM process was completed. Three different treatment conditions, namely as deposited (without HIP treatment), HIP treated at $1100{ }^{\circ} \mathrm{C}$ with a pressure of $160 \mathrm{MPa}$, and HIP treated at $1175{ }^{\circ} \mathrm{C}$ with a pressure of $160 \mathrm{MPa}$ for $2 \mathrm{~h}$, were selected to assess the effect of HIP treatment on the microstructure and mechanical properties of the samples.

Microstructural Characterization and Mechanical Properties Testing. The densities of the SLM-processed specimens after different treatment process were calculated based on the Archimedes principle, using a TG320 electronic balance.

Samples for metallographic examination were prepared following the standard grinding and polishing procedures, and some of the samples were then etched in a solution consisting of $50 \%$ $\mathrm{HCl}$ and $50 \% \mathrm{HNO}_{3}$. The as polished samples were used for porosity measurement and crack observation using a LEICA DMI5000M optical microscope; while the etched samples for microstructural characterization and analysis of the size and distribution of the precipitates, using a QUANTA 400FEG scanning electron microscope.

Tensile tests according to ASTM E8 standard were performed at room temperature using a ZWICK Z020 machine. The SEM technique was then used to examine the fracture surfaces of the samples tested.

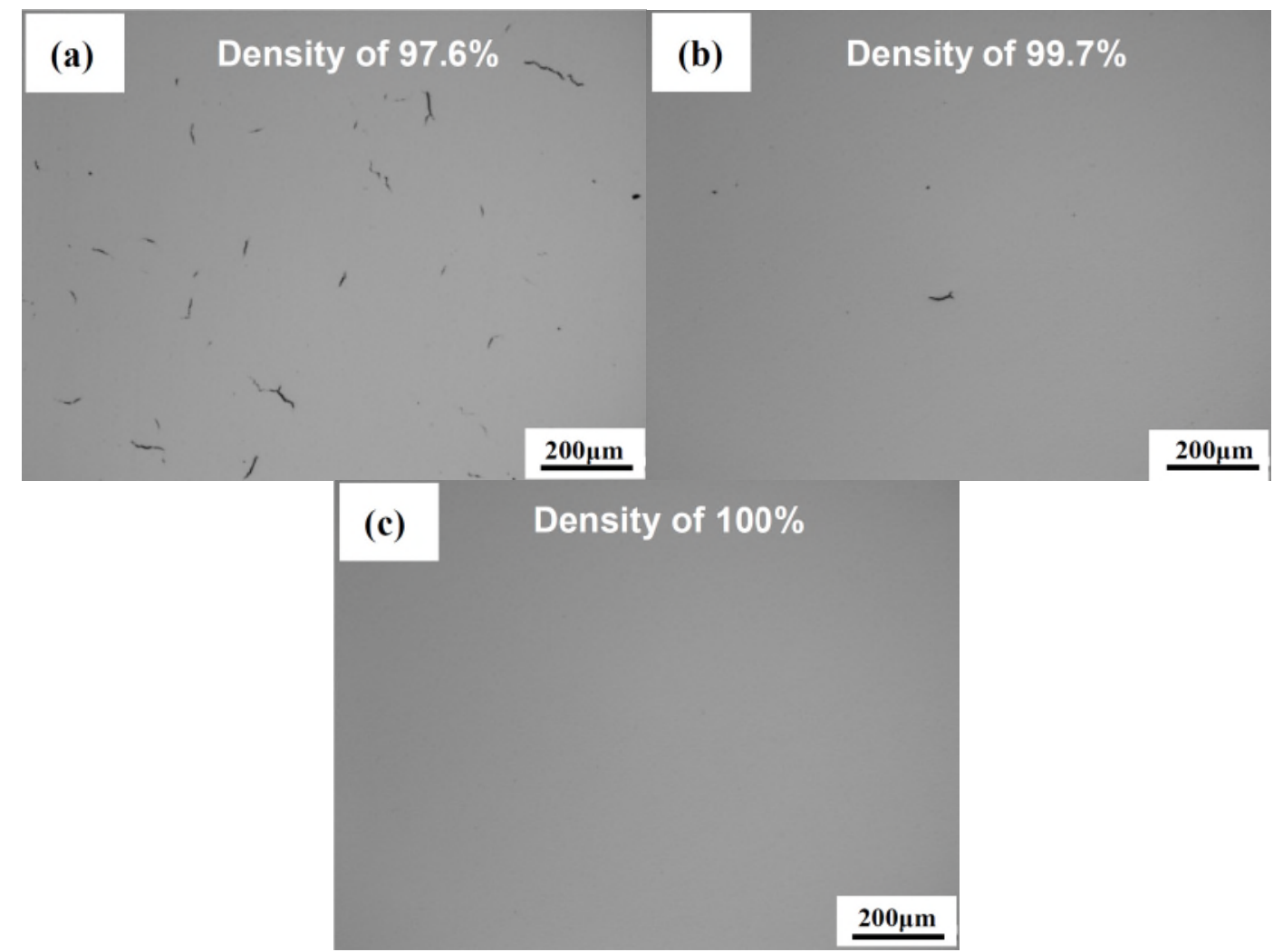

Fig. 2 Defects of SLM-processed Hastelloy-X samples using different HIP: (a)as-deposited; (b)1100 ${ }^{\circ} \mathrm{C} / 160 \mathrm{MPa} / 2 \mathrm{~h}$; (c) $1175{ }^{\circ} \mathrm{C} / 160 \mathrm{MPa} / 2 \mathrm{~h}$.

\section{Results and Discussion}

The Influence of HIP on Eliminating Defects of SLM-Processed Samples. Optical micrographs of the SLM-processed Hastelloy-X samples, with different HIP conditions, are shown in Fig. 2. A large number of cracks were found on the as-deposited surface, the average size of which is about $60 \mu \mathrm{m}$. In addition, micro-pores with a size of several micrometers were also observed. The density of the SLM sample was about $97.6 \%$ (Fig. 2a). After HIP treatment at $1100{ }^{\circ} \mathrm{C}$ with a pressure of 
$160 \mathrm{MPa}$ for $2 \mathrm{~h}$, the number of cracks and micro-pores of the SLM samples were noticeably reduced to a much lower level. The density of the sample was about $99.7 \%$, which was increased by $2.1 \%$, compared with the as-deposited sample (Fig. 2b). As to the sample HIP treated at $1175^{\circ} \mathrm{C}$, the cracks and the micro-pores of the SLM specimen were completely eliminated, and the density of the sample was increased to almost $100 \%$ (Fig. 2c)

It can be seen from Fig. 2 that the HIP treatment can effectively reduce defects, such as cracks and micro-pores, in the Hastelloy X samples prepared by the SLM process. As a result, the densities of the SLM samples were improved. Moreover, as the HIP temperature increased, the number of cracks and micro-pores of the SLM samples decreased, leading to SLM samples being almost fully dense. This was mainly due to i) the gradual closure of the cracks and micropores in the SLM samples under high pressure, and ii) material diffusion under high temperature.

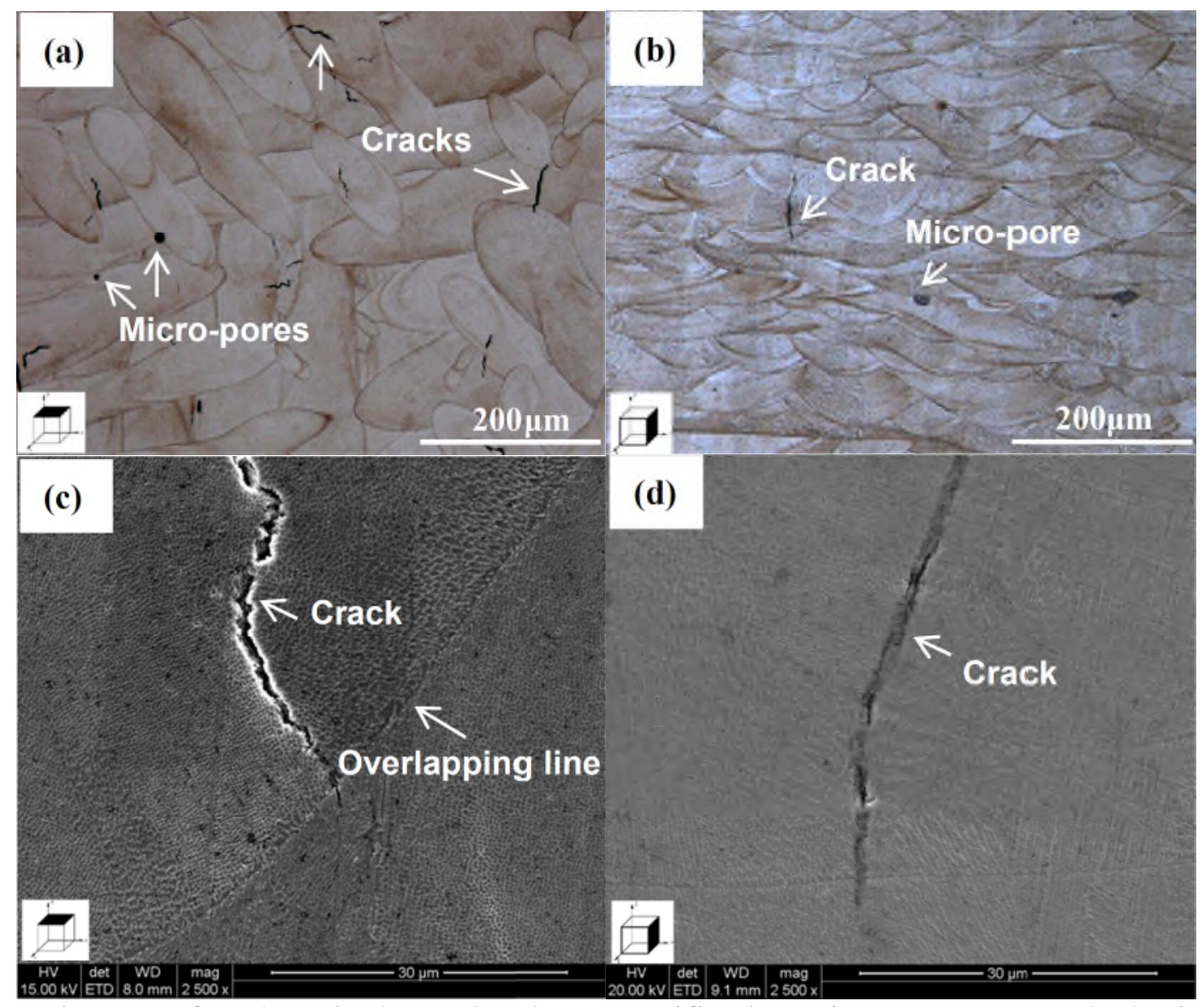

Fig. 3 SEM images of as-deposited samples: low-magnification microstructures on the horizontal cross-section (a) and vertical cross-section(b); high-magnification microstructures on the horizontal cross-section (c) and vertical cross-section(d).

The Influence of HIP on Microstructures of SLM-processed Samples. Fig. 3 shows the SEM images of the transverse and the longitudinal cross-sections (Fig. 3a and b, respectively) of the as-deposited Hastelloy-X specimens, on which great differences can be observed. The elongated oval melt tracks can be clearly seen, of which widths were similar to that of the laser spot $(100 \mu \mathrm{m})$. The melt tracks of different layers were at a certain angle, which was mainly related to the rotation angle of the laser scanning direction set in the SLM parameter (Fig. 3a). Molten pool boundaries can be observed in the as-deposited sample with typical arch-shape curves. The molten pool depth was about $50 \mu \mathrm{m}$, penetrating 2.5-layer thickness. The neighboring layers had a good metallurgical bonding (Fig 3b). In addition, cracks about $50 \mu \mathrm{m}$ long and micro-pores with a size of several micrometers were observed in Fig. 3a and Fig. 3b, as well as longitudinal cracks penetrating several deposition layers in the Z-direction. In Fig. $3 c$ and d, higher magnification micrographs of the as-deposited sample are shown. In addition to the visible cracks, it was found that the solidification 
method of the SLM process was grown in a cellular crystal. The cellular grains were actually a cross-section of the columnar grains. Due to the rapid melting and subsequent solidification of the material, the grain sizes were very fine and no precipitates were observed in the microstructure (Fig. $3 \mathrm{c}, \mathrm{d})$.
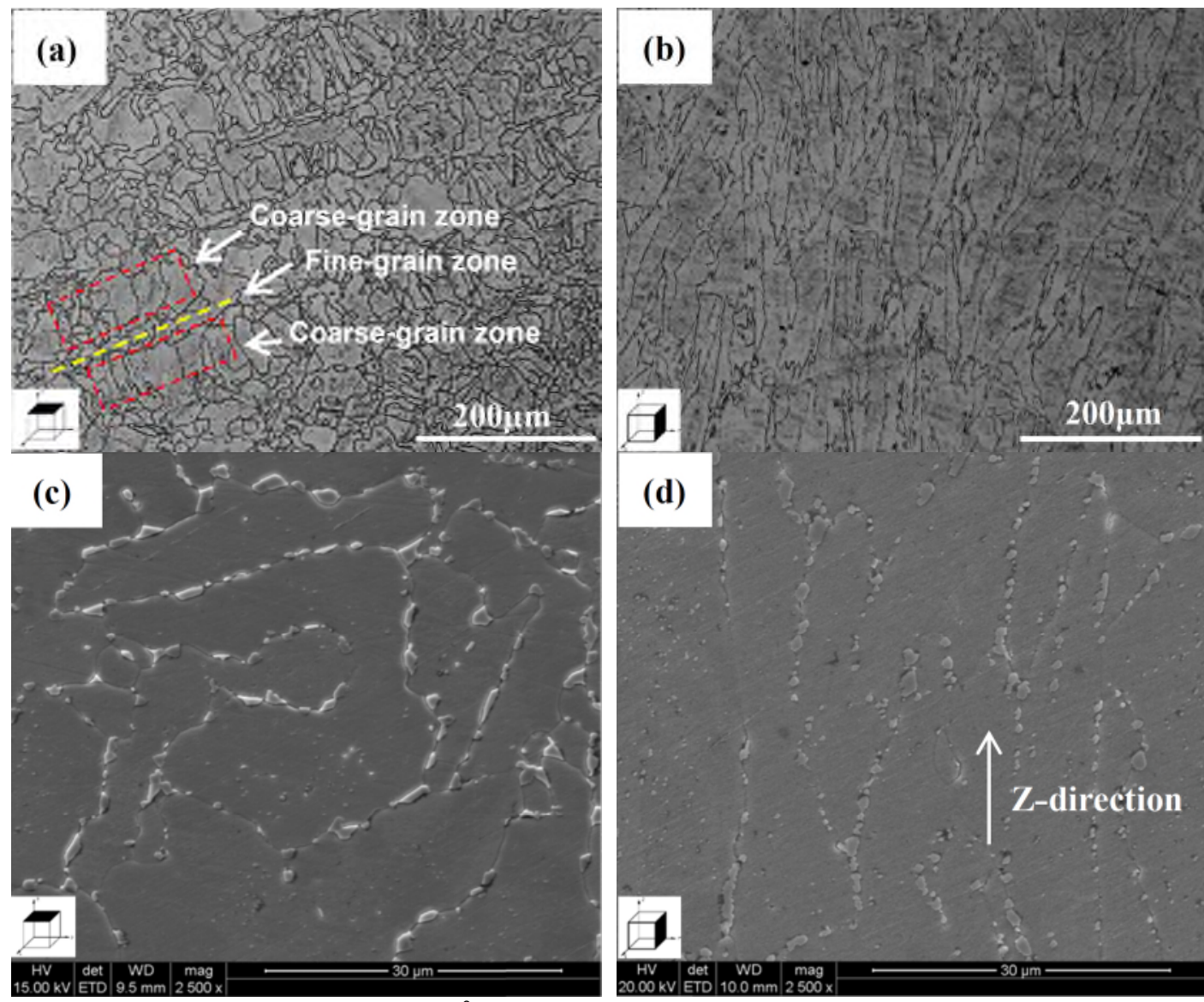

Fig. 4 SEM images of samples after $1100^{\circ} \mathrm{C} / 160 \mathrm{MPa} / 2 \mathrm{~h}:$ low-magnification microstructures on the horizontal cross-section (a) and vertical cross-section(b); high-magnification microstructures on the horizontal cross-section (c) and vertical cross-section(d).

After the as-deposited sample was subjected to HIP treatment at $1100{ }^{\circ} \mathrm{C}$ with a pressure of 160 $\mathrm{MPa}$ for $2 \mathrm{~h}$, equiaxed grains of $10 \sim 50 \mu \mathrm{m}$ in size were observed on its transverse cross-section (Fig. 4a). The melt tracks and the molten pool boundaries disappeared. However, the laser scanning direction can still be deduced from the distribution of the grains. In addition, strips of coarse grains were intercalated with strips of fine grains. This was mainly due to the line-by-line scanning mode of the SLM process. The adjacent scanning lines had overlapping zones, these zones were subjected to 2 melting process, leading to the grain growth in the region (Fig. 4a). A large amount of chain-like precipitates appeared on the grain boundaries, the sizes of which range from about 1-4 $\mu \mathrm{m}$. There were also some fine precipitates with a size of less than $1 \mu \mathrm{m}$ within the grains (Fig. 4c). These precipitates were mainly chromium-rich $\mathrm{M}_{23} \mathrm{C}_{6}$ and molybdenum-rich $\mathrm{M}_{6} \mathrm{C}$ according to the literature [11-14].

There were still some cracks and micro-pores observed on the low-magnification micrograph of the longitudinal cross-section of the specimen (Fig. 4b), which were consistent with the results observed in Fig. 2b. In addition, it was found that the elongated columnar grains with a relatively large aspect ratio had an average grain length of about $200 \mu \mathrm{m}$ and an average width of about $40 \mu \mathrm{m}$. Such a grain extended through about 20 deposited layers. The growth of the columnar grains was mainly along the Z-axis, and the grain growth orientation was slightly different. On one hand, this was because the grains tended to grow along the maximum temperature gradient along which heat dissipation was the fastest. During the SLM process, the under deposited part had a lower 
temperature and high thermal conductivity, which led to heat dissipation being fastest in the $\mathrm{Z}$ direction. On the other hand, the grain tended to grow epitaxially along the original crystallographic orientation, associating crystallization [15-17]. From the SEM micrograph of a higher magnification on the longitudinal cross-section (Fig. 4d), it can be seen that fine precipitates distributed both on the grain boundaries and within the grains (Fig. 4d). The average size of the precipitates at the grain boundaries was $1 \mu \mathrm{m}$, while some grains had a size of about $3 \mu \mathrm{m}$. While the precipitates within the grains were noticeably smaller, being less than $1 \mu \mathrm{m}$. Since the grains had elongated columnar structure grown along the $\mathrm{Z}$ axis, the precipitates also tended to distribute along the $\mathrm{Z}$-axis both on the grain boundaries and within the grains (Fig. 4d).

As to the samples subject to HIP treatment at $1175^{\circ} \mathrm{C}$ with a pressure of $160 \mathrm{MPa}$ for $2 \mathrm{~h}$, there was little difference between the microstructure of its longitudinal and transverse cross-section (Fig. $5 \mathrm{a}, \mathrm{b})$. The grains were all equiaxed and have grown up to about $150 \mu \mathrm{m}$ in size. Laser scanning trajectory features, cracks and micro-pores disappeared, and the microstructures tended to show a higher level of homogenization and densification. Lamellar precipitates were observed at the grain boundaries from SEM micrographs of higher magnification. The size of the precipitates was significantly increased, and the spacing between intergranular phases was small, which almost touched each other, compared with the sample subject to the other set of HIP processing parameters. Meanwhile, the particulate precipitates inside the grains were also obviously grown, with size increasing to $3 \mu \mathrm{m}$. However the amount of the precipitates in the grains was relatively reduced (Fig. $5 \mathrm{c}, \mathrm{d})$.
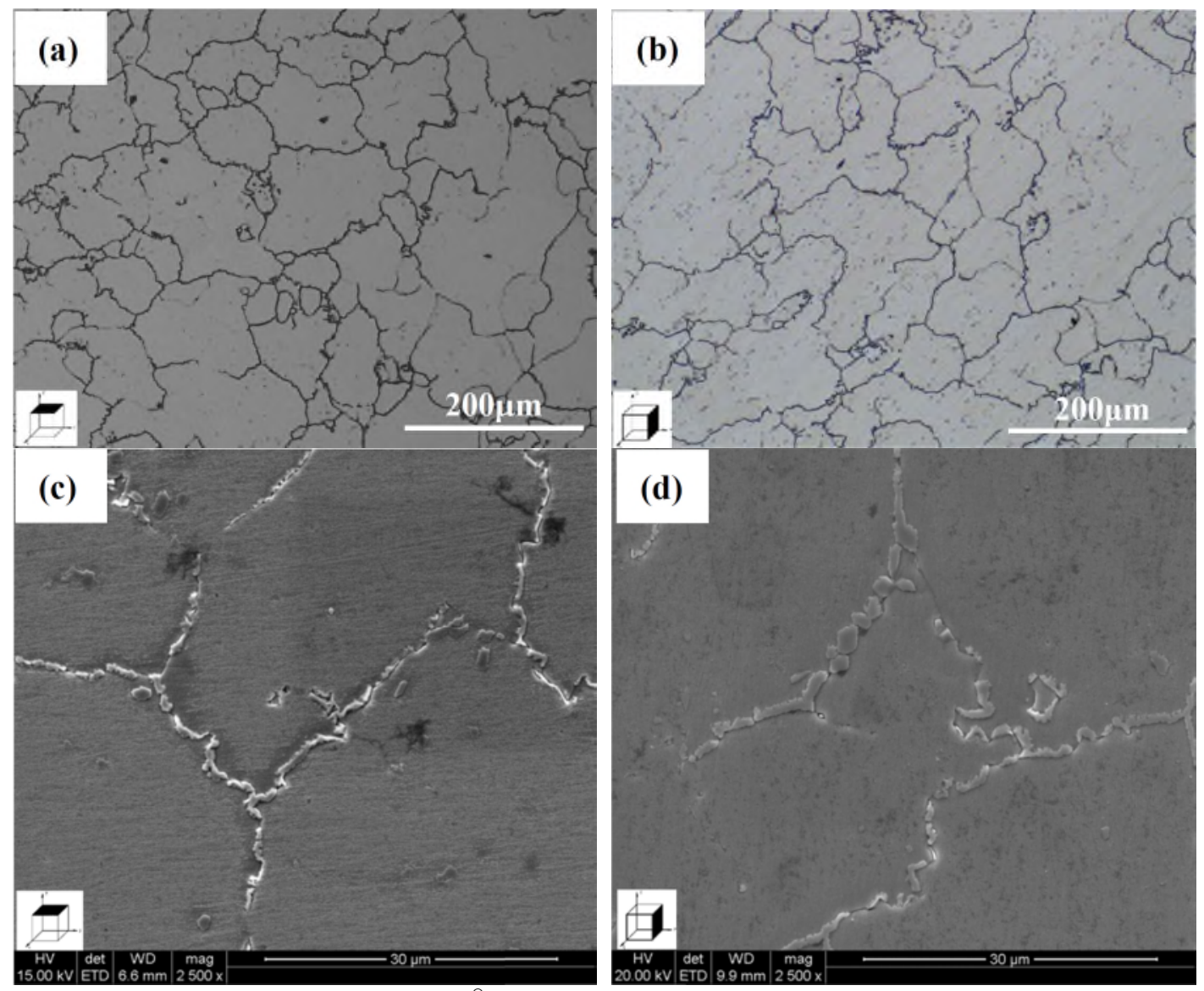

Fig. 5 SEM images of samples after $1175{ }^{\circ} \mathrm{C} / 160 \mathrm{MPa} / 2 \mathrm{~h}$ : low-magnification microstructures on the horizontal cross-section (a) and vertical cross-section(b); high-magnification microstructures on the horizontal cross-section (c) and vertical cross-section(d).

By comparing Fig. 3, Fig. 4 and Fig. 5, it was found that the microstructure evolution of Hastelloy X alloy SLM samples was strongly temperature-dependent. The Hastelloy X alloy recrystallized after being HIP treated at $1100{ }^{\circ} \mathrm{C}$ with a pressure of $160 \mathrm{MPa}$ for $2 \mathrm{~h}$, as indicated by 
the disappearance of the melt tracks and the molten pool boundaries in the as-deposited samples. Moreover, the transverse microstructure evolved into equiaxed grains and the longitudinal microstructure evolved into columnar grains. There were also fine precipitates in the transverse and longitudinal microstructures. When the pressure and the time of the HIP treatment remained the same but the temperature increased to $1175{ }^{\circ} \mathrm{C}$, it was found that all the transverse and longitudinal microstructures evolved into equiaxed grains. The grain size of the matrix and the precipitates grew at least 3 times larger. Meanwhile, the precipitates inside the grains partly dissolved. Grain growth was mainly affected by the grain boundary migration mechanism which is significantly temperature dependent. With the increase of the HIP temperature, the grain boundary migration was accelerated. The grain growth process can be seen as a thermally activated process. On the other hand, it can be concluded from Fig. 5 that the number of the precipitates decreases with the increase of the grain size, indicating that the precipitate number was related to the grain size of the Hastelloy X alloy. A similar phenomenon was also observed in the study of Hastelloy N alloys by R.E. Gehlbach [18]. When Mo or Si and other elements were added to promote the formation of $\mathrm{M}_{6} \mathrm{C}$ carbides, it was found that the number of precipitates increased and the grain size decreased accordingly.

The Influence of HIP on Mechanical Properties of SLM-processed Samples. Table 3 shows the tensile properties of the SLM-processed Hastelloy-X samples subject to different HIP treatments. It can be seen that the tensile properties of the SLM samples were higher than those of the materials traditionally prepared by rolling or forging. When the sample condition changed from as-deposited to HIP treated at $1100{ }^{\circ} \mathrm{C} / 160 \mathrm{MPa} / 2 \mathrm{~h}$ and $1175^{\circ} \mathrm{C} / 160 \mathrm{MPa} / 2 \mathrm{~h}$, the tensile strength decreased by $6.5 \%$ and $7.8 \%$ respectively, and the yield strength decreased by $24.5 \%$ and $50.7 \%$ respectively; while the elongation increased by $24.6 \%$ and $36.2 \%$ respectively, and the area shrinkage increased by $5.6 \%$ and $26.9 \%$ respectively. On the whole, the room temperature strength of the samples after HIP treatment decreased, while the plasticity was improved. In particular, the yield strength and elongation of the sample changed significantly. The factors that affected the yield strength of the material are bond, atomic nature and microstructure. For the same type of material, the yield strength is mainly affected by its microstructure. After HIP treatment, a large amount of carbide precipitates appeared at the grain boundaries and inside the grains. As the temperature increases, the precipitates and the matrix grains grew in size at the same time, while the tensile strength decreases. Therefore, the size of the precipitates and the matrix grains were the main factors that influenced the SLM-processed Hastelloy X samples.

Table 3. Tensile properties of SLM-processed Hastelloy-X samples.

\begin{tabular}{ccccc}
\hline Treatment condition & $\sigma_{\mathrm{b}} / \mathrm{Mpa}$ & $\sigma_{0.2} / \mathrm{Mpa}$ & $\delta_{5} / \%$ & $\psi / \%$ \\
\hline As-deposited & 770 & 570 & 34.5 & 57.5 \\
$1100{ }^{\circ} \mathrm{C} / 160 \mathrm{MPa} / 2 \mathrm{~h}$ & 720 & 430 & 43 & 60.7 \\
$1175{ }^{\circ} \mathrm{C} / 160 \mathrm{MPa} / 2 \mathrm{~h}$ & 710 & 281 & 47 & 42 \\
Wrought standard & $\geq 690$ & $\geq 275$ & $\geq 30$ & - \\
(HB5497-92) & & & & \\
\hline
\end{tabular}

The SEM fractographs of the SLM-processed Hastelloy X tensile samples are shown in Fig. 6. The lower-magnification micrograph of the as-deposited sample shows that the fracture surface was rough, and the necking phenomenon before fracturing can also be seen (Fig 6a). And the higher-magnification micrograph of the fracture surface shows the dimple and tear features, indicating a ductile failure mode (Fig 6b). After being HIP treated at $1100{ }^{\circ} \mathrm{C}$ and $160 \mathrm{MPa}$ for $2 \mathrm{~h}$, the typical cup-cone feature and the necking phenomenon can be observed on the lower-magnification micrograph of the fracture surface (Fig 6c). And the higher magnification micrograph shows obvious equiaxed dimples, indicating the material had excellent plasticity (Fig 6d). As to the samples subject to HIP treatment at $1175^{\circ} \mathrm{C}$ and $160 \mathrm{MPa}$ for $2 \mathrm{~h}$, the fracture surface appeared relatively flat, and necking was not obvious on this sample. In addition, a granular fracture surface was formed (Fig 6e). Equiaxed dimples and secondary cracks that are typical features of the 
ductile failure mode can be observed on the higher-magnification micrograph (Fig 6f).
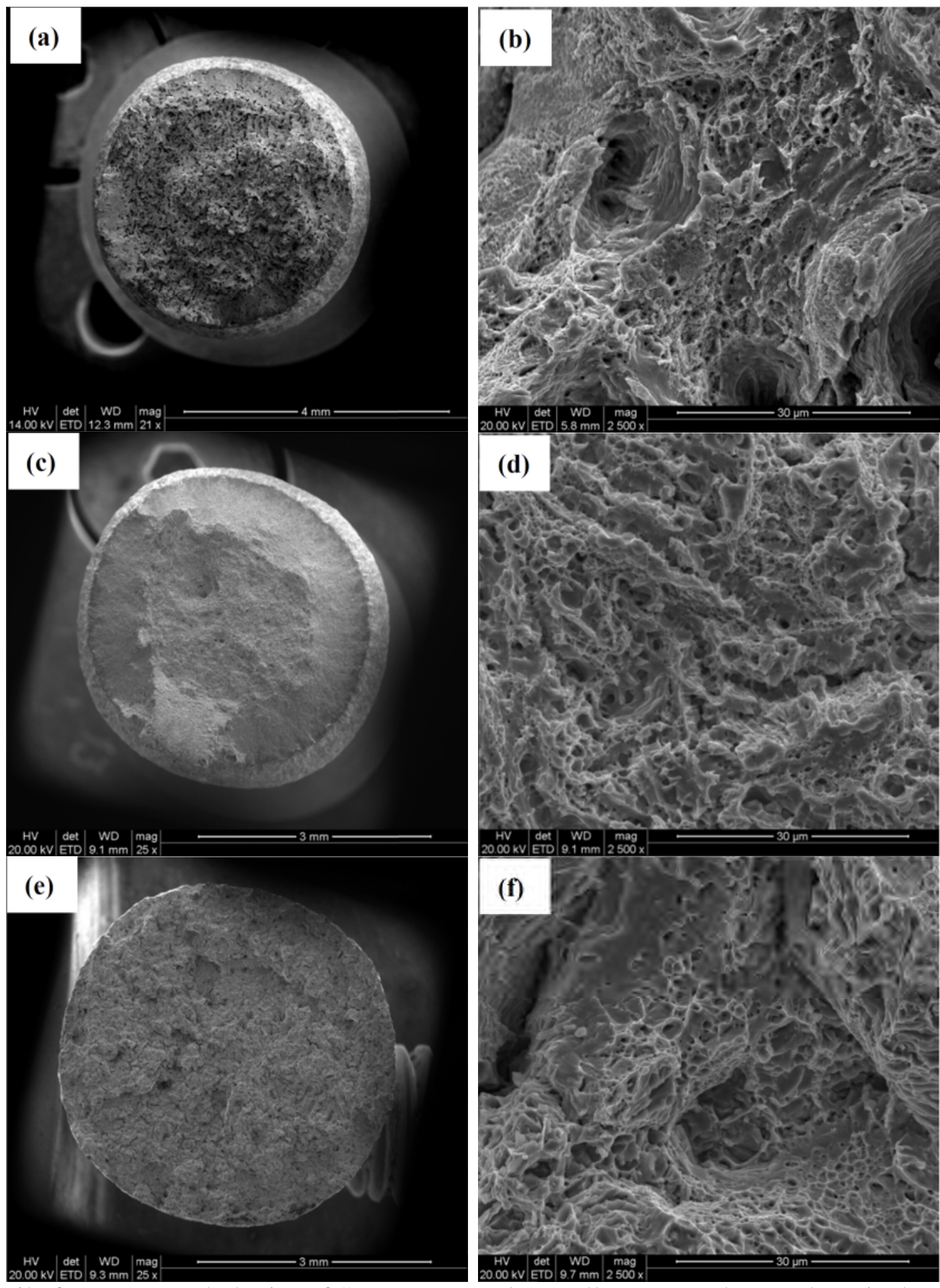

Fig. 6 Tensile fracture morphologies of SLM-processed Hastelloy X samples: as-deposited at low (a) and high (b) magnification; HIP of $1100^{\circ} \mathrm{C} / 160 \mathrm{MPa} / 2 \mathrm{~h}$ at low (c) and high (d) magnification; HIP of $1175{ }^{\circ} \mathrm{C} / 160 \mathrm{MPa} / 2 \mathrm{~h}$ at low (e) and high (f) magnification.

\section{Conclusion}

(1) HIP can effectively eliminate the defects such as cracks and micro-pores in SLM-processed samples, and the defects decreased gradually with the increase of HIP temperature. A nearly full dense SLM-processed sample was obtained at HIP of $1175^{\circ} \mathrm{C} / 160 \mathrm{MPa} / 2 \mathrm{~h}$.

(2) The microstructure evolution rule as follows: cellular crystal in both horizon and vertical directions, no precipitates (as-deposited) $\rightarrow$ equiaxed crystal with size of $10-50 \mu \mathrm{m}$ in horizon 
direction and columnar crystal with size of $200 \mu \mathrm{m}$ in vertical direction, chain-like precipitates distributed at grain boundaries $\left(1100{ }^{\circ} \mathrm{C} / 160 \mathrm{MPa} / 2 \mathrm{~h}\right.$ HIP processed) $\rightarrow$ equiaxed crystal with size of $150 \mu \mathrm{m}$ in both horizon and vertical directions, plate-like precipitates distributed at grain boundaries with size triple increased $\left(1175^{\circ} \mathrm{C} / 160 \mathrm{MPa} / 2 \mathrm{~h}\right.$ HIP processed).

(3) Ductile fracture occurred in both SLM deposited and HIP processed parts during room temperature tensile tests, while all tested samples behaved higher mechanical properties than traditional wrought parts. The ductility of HIP processed samples enhanced and tensile properties decreased compared with SLM deposited samples, which was mainly due to the precipitation of carbides and the grain size.

\section{Acknowledgement}

In this paper, the research was sponsored by Science and Technology Commission of Shanghai Municipality (Project No. 15111108000 and Project No. 2015-101).

\section{References}

[1] M. Pakniat, F. M. Ghaini, M. J. Torkamany, Hot cracking in laser welding of Hastelloy X with pulsed Nd:YAG and continuous wave fiber lasers, Mater. Des. 106 (2016) 177-183.

[2] D. Bhattacharyya, J. Davis, M. Drew, et al. Characterization of complex carbide-silicide precipitates in a Ni-Cr-Mo-Fe-Si alloy modified by welding, Mater. Charact. 105 (2015) 118-128.

[3] W. Abuzaid, H. Sehitoglua, J. Lambros, Plastic strain localization and fatigue micro-crack formation in Hastelloy-X, Mater. Sci. Eng. (A), 561 (2013) 507-519.

[4] D. J. Wu, G. Y. Ma, F. Y. Niu, D. M. Guo, Pulsed laser welding of Hastelloy C-276: high-temperature mechanical properties and microstructure, Mater. Manuf. Process. 28(5) (2013) 524-528.

[5] S. Bremen, W. Meiners, A. Diatlov, Selective laser melting, Laser Technik J. 9(2) (2012) 33-38.

[6] K. A. Mumtaz, P. Erasenthiran, N. Hopkinson, High density selective laser melting of Waspaloy®, J. Mater. Process. Technol. 195(1) (2008) 77-87.

[7] F. Wang, Mechanical property study on rapid additive layer manufacture Hastelloy® X alloy by selective laser melting technology, Int. J. Adv. Manuf. Technol. 58(5-8) (2012) 545-551.

[8] Roettger Arne, Geenen Karma, Windmann Matthias, Binner Florian, Theisen Werner. Comparison of microstructure and mechanical properties of $316 \mathrm{~L}$ austenitic steel processed by selective laser melting with hot-isostatic pressed and cast material, Mater. Sci. Eng. (A), 678 (2016) 365-376.

[9] C. Cai, B. Song, P. J. Xue, Q. S. Wei, J. M. Wu, W. Li, Y. S. Shi, Effect of hot isostatic pressing procedure on performance of Ti6Al4V: Surface qualities, microstructure and mechanical properties, J. Alloys Compd. 686 (2016) 55-63.

[10] Martin Trunec, Jens Klimke, Zhijian James Shen, Transparent alumina ceramics densified by a combinational approach of spark plasma sintering and hot isostatic pressing, J. Eur. Ceram. Soc. 36(16) (2016) 4333-4337.

[11] J. C. Zhao, M. Larsen, V. Ravikumar, Phase precipitation and time-temperature-transformation diagram of Hastelloy X, Mater. Sci. Eng. A, 293(1) (2000) 112-119.

[12]J. Belan. G. C. P. and T. C. P. phases presented in nickel-base superalloys, Mater. Today: Proceedings, 3(4) (2016) 936-941. 
[13]X. Z. Qin, J. T. Guo, C. Yuan, et al. Precipitation and thermal instability of M23C6 carbide in cast Ni-base superalloy K452, Mater. Lett. 62(2) (2008) 258-261.

[14] G. Bai, J. LI, R. HU, et al. Effect of temperature on tensile behavior of Ni-Cr-W based superalloy, Mater. Sci. Eng. A, 528(4) (2011) 1974-1978.

[15]C. M. Liu, X. J. Tian, H. B. Tang, H. M. Wang, Microstructural characterization of laser melting deposited Ti-5Al-5Mo-5V-1Cr-1Fe near $\beta$ titanium alloy, J. Alloys Compd. 572 (2013) 17-24.

[16]J. Li, H. M. Wang, Microstructure and mechanical properties of rapid directionally solidified Ni-base superalloy Rene41 by laser melting deposition manufacturing, Mater. Sci. Eng. A, 293(1) (2000) 112-119.

[17]C. M. Liu, H. M. Wang, X. J. Tian, H. B. Tang, D. Liu, Microstructure and tensile properties of laser melting deposited Ti-5Al-5Mo-5V-1Cr-1Fe near $\beta$ titanium alloy, Mater. Sci. Eng. A, 586 (2013) 323-329.

[18]R. E. Gehlbach, J. H. E. Mccoy, Phase instability in Hastelloy N, International Symposium on Structural Stability in Superalloys, Penn: Seven Springs, 1968, 11, 346-366. 